\title{
Clinico-Pathological and Audiological Assessment of Tympanosclerosis-A Study
}

\author{
Dr. B.Ramchandra Rao ${ }^{1}$, Dr.G.Parasuram ${ }^{2}$ Dr. S.Suryaprakasa Rao ${ }^{3}$ \\ ${ }^{1}$ (Assistant Professor, Department Of ENT, Andhra Medical College, Vishakapatnam.) \\ ${ }^{2}$ (Associate Professor, ENT, Andhra Medical College.) \\ ${ }^{3}$ (Professor Of ENT, Andhra Medical College)
}

\begin{abstract}
:
Aims and objectives of the study:

1. Age and sex prediction for the occurrence of Tympanosclerosis..

2. Common sites of involvement in the tympanic membrane.

3. To determine the hearing status in patients afflicted with Tympanosclerosis.

4. Histological pattern of the excised plaques
\end{abstract}

Materials And Methods: The study was conducted in those patients attending outpatient department of Andhra Medical College, Government ENT hospital for a period of twelve months. In the study period, about 69,750 patients attended to Out Patient Department with complaints of ear, nose and throat. 24,400 (34.9\%) patients attended with ear symptoms, out of them 100 cases of tympanosclerosis were selected. In some cases, there is associated Chronic Suppurative Otitis Media of tubotympanic type with inactive mucosal disease. Sex preponderance, age variations, presenting symptoms, tympanic membrane quadrant involved, type of deafness, pathological study of tympanosclerotic plaque were given priority in this study.

Conclusion: To conclude, females are affected more with Tympanosclerosis when compared to males (58:42). Age group of 21-40 yrs is most commonly involved. Posterosuperior quadrant is identified as most common quadrant involved with tympanosclerosis in pars tensa of the tympanic membrane. Conductive deafness is the presenting symptom in most of the patients, rather than discharging ear or sensorineural hearing loss.

Keywords: Tympanosclerosis, Tympanoplasty, Chronic suppurative otitis media, Conductive deafness.

\section{Introduction}

Tympanosclerosis is a condition which is still a dilemma to deal with for the ENT surgeon. Patient with only tympanosclerosis in the tympanic membrane will not often seek consultation. Patients attend ENT department only when there is discharge or deafness of moderate grade. By this time, the patient would have developed associated Chronic Suppurative Otitis Media either with central perforation or with cholesteatoma ${ }^{1}$ and sometimes associated with early otosclerosis.

Acute Otitis Media usually resolves spontaneously or after medication. In some cases, it ends up as Serous otitis media (glue ear), Chronic Suppurative Otitis Media, Adhesive Otitis Media and Tympanosclerosis.

Tympanosclerosis is the terminal irreversible stage of a pathological process based on the inflammation of middle ear mucosa which has not regressed and does not continue as an inflammatory process. ${ }^{2,3}$

It is a non functional and inert repair phenomenon. However inspite of its inert nature, it is an important clinicopathological entity as it can cause stiffness of the sound conducting mechanism of the ear. Tympanosclerosis most frequently affects the tympanic membrane, but the ossicular ligaments, interosseous joints, muscle tendons and submucosal space can also be affected causing varying degrees of immobility of the ossicular chain (Igarashi et aI. $)^{4}$. Pathologically, tympanosclerosis is the end point of a healing process in which the collagen in fibrous tissue hyalinizes, loses its structure and fuses into a homogeneous mass (Schuknecht). Thereafter calcification and perhaps ossification may occur to a variable extent. Inflammation is dynamic and evolutionary in nature where as the sclerosis is the final stage process.

Clinical reports of surgical findings suggest that tympanosclerosis is rare in active ears (Gristwood and Venables) and particularly in ears with a cholesteatoma (Plester) ${ }^{3}$, but pathological studies of temporal bones would not support this distinction (Meyerhoff,. Kim and Paparella).

Though clinical intuition might suggest that tympanosclerosis is irreversible, series that have followed up ears with tympanosclerosis of the tympanic membrane secondary to childhood otitis media for many years have shown it to disappear in a proportion (Ambegaoker, Brown and Richards; Tos, Bonding and Poulsen.) 


\section{Materials And Methods}

The material for the study was chiefly those patients who attended the Out Patient Department of Government E.N.T hospital with a history of hard of hearing and ear discharge. In this study, cases attending E.N.T hospital for a period of 12 months were reviewed and 100 cases were selected and recorded.

Every case of tympanosclerosis was examined, investigated and followed up. All the cases were examined thoroughly after taking detailed history regarding the deafness, ear discharge, recurrent attacks of cold and allergy and any history of previous surgeries. Clinical examination was done with Bull's eye lamp and appearance of tympanic membrane was noted.

Clinical assessment of hearing was made by the tuning fork tests and pure tone audiometry. Examination under microscope and otoendoscope were done to visualize the condition of external ear, tympanic membrane, tympanosclerotic plaques, any perforations in the tympanic membrane and visible middle ear, to confirm the previous findings. The quadrant of pars tensa involved with tympanosclerosis is specifically noted. Every case of tympanosclerosis was screened and the cases which required surgery were operated. The type of surgical method was decided on the basis of $\mathrm{X}$ - ray of both mastoids, the Pure Tone Audiogram and intraoperative findings in the middle ear and mastoid.

In the process of investigation and treatment, importance was given to clinical findings and hearing loss and pathological study.

\section{Inclusion criteria:}

1. Patients with tympanosclerosis with hard of hearing.

2. Patients with tympanosclerosis associated with Chronic suppurative otitis media of tubotympanic type, inactive mucosal disease.

\section{Exclusion criteria:}

1. Tymapnosclerosis with cholesteatoma.

2. Pure Otosclerosis

3. Otosclerosis with Chronic Suppurative Otitis Media.

4. History of previous surgeries.

III. Observation And Results

The total number of patients selected for the study was 100 .

\section{Sex distribution:}

\begin{tabular}{|l|l|}
\hline SEX & INCIDENCE \\
\hline Males & 42 \\
\hline Females & 58 \\
\hline
\end{tabular}

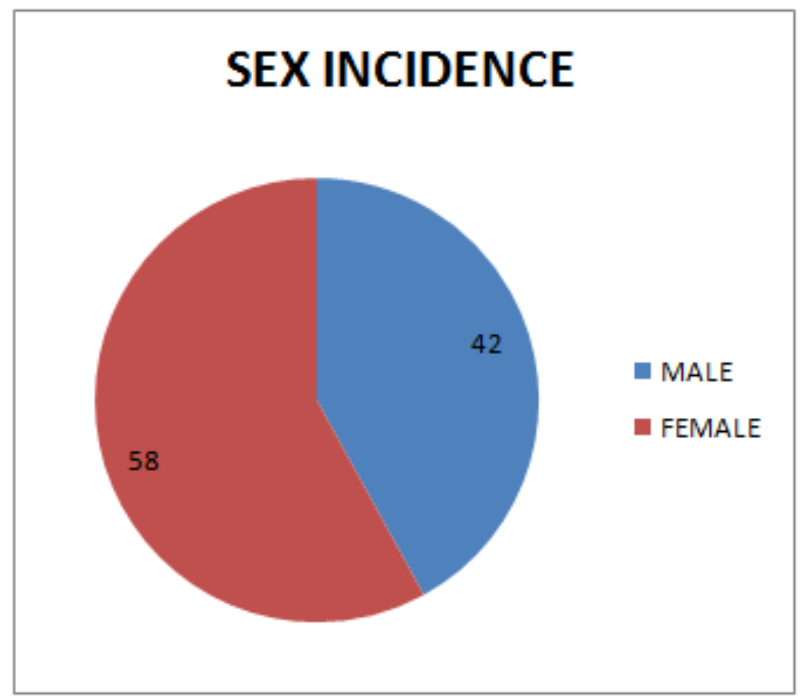

Among the study group which consisted of 100 patients, 42patients were males and 58 were females with female predominance. 


\section{Age distribution:}

\begin{tabular}{|l|l|l|}
\hline AGE GROUP IN YEARS & NO OF CASES & PERCENTAGE \\
\hline $0-20$ & 12 & $12 \%$ \\
\hline $21-40$ & 72 & $72 \%$ \\
\hline $41-60$ & 16 & $16 \%$ \\
\hline
\end{tabular}

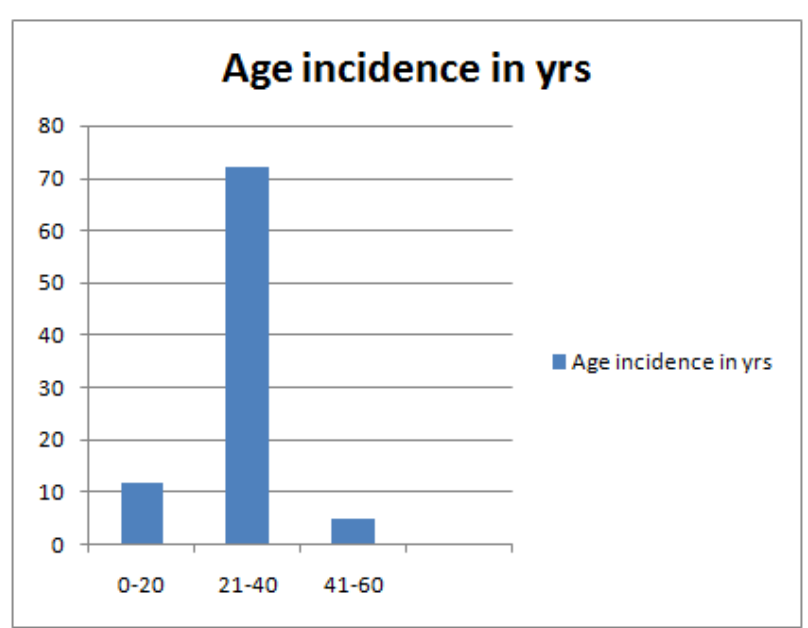

In this series, it was observed that most of the patients treated belonged to the age group of 21-40 years (72\%) while the other age group 40-60 years were found to be $16 \%$ and at the last $0-20$ years (12\%).

\begin{tabular}{|l|l|l|}
\hline $\begin{array}{l}\text { PRIMARY PRESENTING } \\
\text { COMPLAINT }\end{array}$ & NO OF CASES & PERCENTAGE \\
\hline Deafness & 60 & $60 \%$ \\
\hline Ear discharge & 26 & $26 \%$ \\
\hline Non otological complaints & 14 & $14 \%$ \\
\hline
\end{tabular}

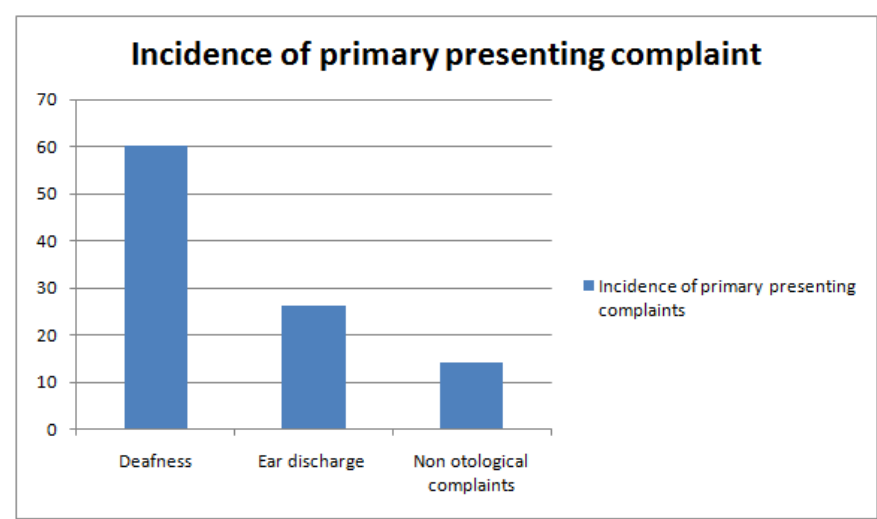

$60 \%$ patients attended with deafness as a primary presenting complaint while $26 \%$ patients with ear discharge and the last $14 \%$ patients who attended with non-otological complaint.

\section{Site of Predilection of Tympanosclerotic Plaque}

\begin{tabular}{|l|l|l|}
\hline Site of tympanosclerotic plaque & No of cases & Percentage \\
\hline Postero superior & 55 & $55 \%$ \\
\hline Antero inferior & 22 & $22 \%$ \\
\hline Postero inferior & 12 & $12 \%$ \\
\hline Antero superior & 11 & $11 \%$ \\
\hline
\end{tabular}




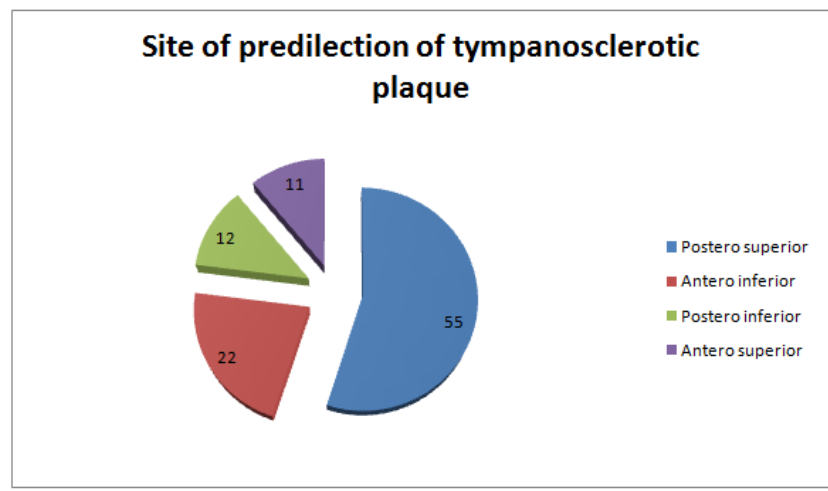

According to the otological findings in our series, the posterosuperior quadrant of pars tensa of the membrane was the most commonly involved area by the tympanosclerotic plaques, followed by anteroinferior, posteroinferior and anterosuperior quadrants. Pars flaccida was not involved in any of the cases by tympanosclerosis.

\section{Incidence of the Type of Deafness}

\begin{tabular}{|l|l|l|}
\hline TYPE OF DEAFNESS & NO OF CASES & PERCENTAGE \\
\hline Conductive & 84 & $84 \%$ \\
\hline Mixed & 12 & $12 \%$ \\
\hline Sensorineural & 4 & $4 \%$ \\
\hline
\end{tabular}

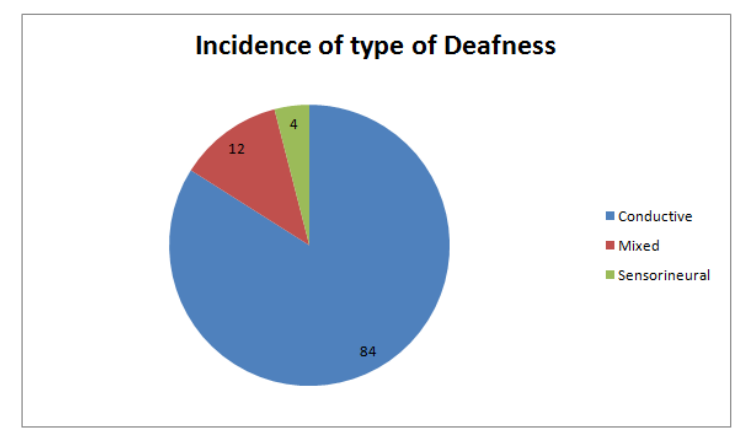

Conductive deafness was identified in $84 \%$ patients while Mixed type of deafness in $12 \%$ and the least sensorineural deafness in $4 \%$. Tympanosclerotic plaques were sent for histopathological examination which were collected during surgery.

\section{Discussion}

In this clinicopathological study of tympanosclerosis, female to male ratio was observed to be $58 \%$ $: 42 \%$. Females were mostly affected probably because the female patients attending with deafness to outpatient department were more in number. The awareness of hearing is increasing day by day in the female population because both females and males are going to the schools and colleges and females are also being employed more in jobs where communication is important.

Significantly $14 \%$ of the patients did not have any otological complaints. These patients had come to the OPD for their non otological complaints and in them tympanosclerosis was just an incidental finding.

The commonest presenting complaint was deafness of varying degrees. Amongst these, $84 \%$ were with conductive type of deafness. Impairment of hearing was mainly the end result of the inflammatory process called Tympanosclerosis, in tympanic membrane, ossicles, inter-osseous joints, foot plate of stapes, middle ear cavity ${ }^{4}$ and mastoid.

Mixed type of deafness was identified in $12 \%$ cases.In the current study, $4 \%$ of the cases had sensorineural hearing loss. It might have occurred due to the involvement of inner ear by tympanosclerosis. $(\mathrm{Gibb})^{6,9}$

In this study, we did not correlate the degree of the hearing loss with the extent of tymapanosclerosis as the hearing loss is also related to the extent of tympanosclerosis in the nooks and corners of middle ear and mastoid, and other associated pathologies like central perforation of tympanic membrane in chronic suppurative otitis media with inactive mucosal disease and such a correlation is liable to be fallacious. 

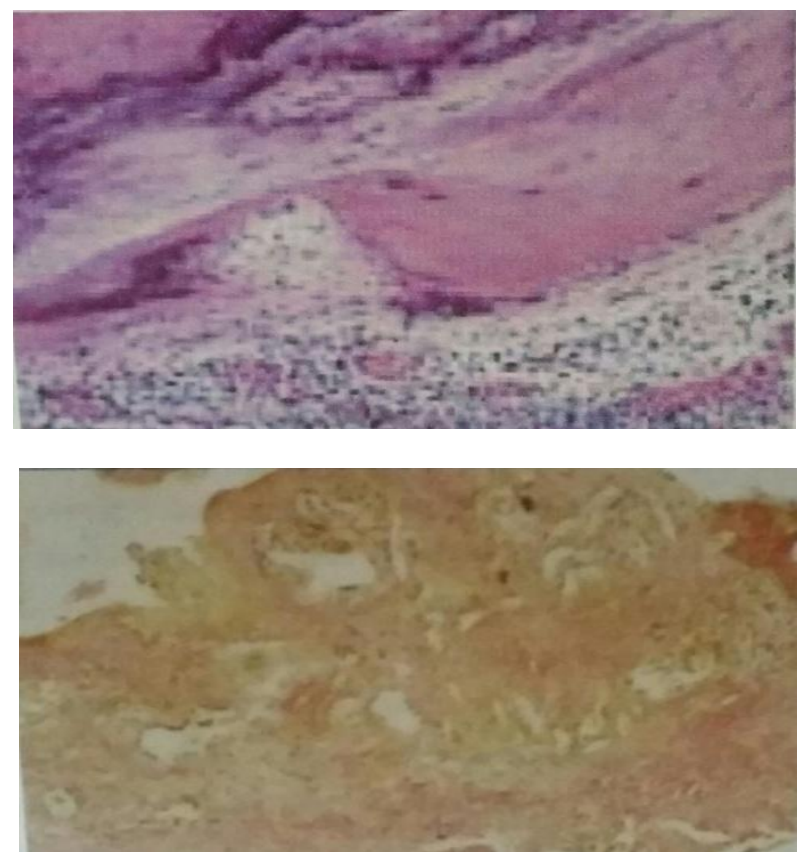

Histology Of Tympanosclerosis: With heamatoxylin and eosin stain reveals dense bundles of collagen with hyaline degeneration and scattered areas of calcification

Katchburian's working. hypothesis of mineralization (Katchburian, 1973) has universal appeal and can 'be confirmed on the basis of observations on tympanosclerosis and otosclerosis. Early stages of mineralization are characterized by the reappearance of matrix vescicles from cells and calcospherules in the collagenous tissue matrix(fibroblasts, inflammatory cells, epithelial cells ${ }^{10,11}$. The membrane of matrix vesicles, which contains calcium and phosphate ions, may become altered due to lack of renewal, followed by loss of water and supersaturation inside the matrix vesicles (Anderson, 1969; Friedmann, Hodges and Graham, 1980). Supersaturation leads to incipient calcification and crystal formation, and will proceed spontaneously, resulting in the production of calcospherules in the collagenous tissue. Progressive mineralization follows with a gradual increase in the number of inclusions, frequently accompanied by mineralization beyond the matrix vesicles. Eventually confluent mineralized masses or plaques are formed. This applies to any bony dysplasia. The matrix vesicles may only be responsible for the mineralization of the non-fibrillar phase of the matrix (Katchburian, 1973) ${ }^{12,13}$. Mineral deposits in the Inter-fibrillar region could lead to the creation of ionic conditions in the matrix, thus facilitating the initial precipitation of calcium phosphate within the collagen fibres and causing dystrophic calcification.

\section{Conclusion}

Tympanoslcerosis is clinicopathological entity of immense importance and is a sequelae of long standing inflammation of the middle ear cleft, most commonly seen in CSOM with central perforation ${ }^{14}$. It can affect almost any part of the tympanic membrane and middle ear cavity. It is symptomatic but may be an incidental finding in otologically asymptomatic patients.

It has female predilection $(58 \% ; 42 \%)$ and occurs in both sexes. Its incidence is common in the $3^{\text {rd }}$ and $4^{\text {th }}$ decades of life though it is not infrequent in other ages.

Commonest site of the tympanosclerosis is the tympanic membrane where poster superior quadrant $(55 \%)$ is involved even though it can affect any quadrant of the pars tensa. ${ }^{15}$

It is predominantly associated with conductive type of deafness (84\%). However in some cases mixed (12\%) and sensorineural deafness $(4 \%)$ may be encountered.

Hearing loss can be alleviated to a great extent in a majority of patients by an appropriate surgery. Results of the surgery are good and not affected by the presence of the plaque unless it is present at a site with some fixity of the sound conducting mechanism, like at the ossicles, inter-osseous joints and stapes footplate ${ }^{16}$

Histopatholigical examination of the plaques by light microscopy after heamatoxylin and eosin stain reveals dense bundles of collagen with hyaline degeneration and scattered areas of calcification. ${ }^{17}$ 


\section{References}

[1]. GRISTWOOD, R. E. and VENABLES, W. N. (1982) Cholesteatoma and tympanosclerosis. In: Cholesteatoma and Mastoid Surgery

[2]. Sheehy JL, House WF. Tympanosclerosis. Arch Otolaryngol 1962; 151-7.

[3]. PLESTER, D. (1971) Tympanosclerosis. Journal of the Otolaryngological Society of Australia, 3, 325-326

[4]. Tos M, Bak Pederson K. Middle- ear mucosa in tympanosclerosis J. Laryngol Otal 1974; 88:119-26.

[5]. Bhaya, MH, Schachern, T.Paperella MM. Pathogenesis of tympanosclerosis. Otolaryngol- Head Neck Surg 1993;109;413-20.

[6]. Gibb AG. President's address. Tympanosclerosis. Proc R Soc Med 1976; 69:155-62.

[7]. Bonnaud, G.La Tympanosclerose, Aspects Histopathogeniques Cliniques et tympeutiques,impri merie Marseille 1971.

[8]. Ferlito A. Pathologia del Otomostoidite Purulenta Cronica AttiDell; Accademia Nazionale dei Lince, S VIII, 1974; 12:53

[9]. Gibb AG. Tympanosclerosis, Acta Otorhinol Belgiga 1971: 25:956.

[10]. Friedmann I, arnol W. In pathology of the ear, Churchill Livingstone; 1993.p.80-6

[11]. Friedmann I,Initiation and stages of mineralization in tympanosclerosis. J. Laryngol Otal 1980: 94- 1215 - 29

[12]. Chang Wang I. Tympanosclerosis. Electron Microscopic study. Acta Otolaryngol 1969;68-72.

[13]. FRIEDMANN, I., HODGES, M. and GRAHAM, M. M. (1980) Tympanosclerosis - an electron microscope study of matrix vesicles. Annals of Otology, Rhinology and Laryngology, 89, 241-245

[14]. Harris I. Tympanosclerosis- a revived clinicopathologic entity. Laryngoscope 1961;71;1488-533

[15]. Jaishinghani VJ, Hunter LL, Li Y, Margolis RH. Quantitative analysis of tympanic membrane disease using video-otoscopy. Laryngoscope 2000,110:1716-30.

[16]. Kamal SA. Surgery of tympanosclerosis. J.Laryngol Otol 1997;111:917-23.

[17]. Ferlito A.. Histopathogenesis of tympanosclerosis. J . Laryngol Otol 1979 ; 96:25-37. 